\title{
PARTIR, QUERENDO FICAR: MIGRAÇÕES E IDENTIDADES NA LITERATURA DE CORDEL
}

\author{
José Welton Ferreira dos Santos Junior* \\ Rejane Vecchia da Rocha e Silva**
}

Resumo: Este artigo apresenta uma leitura sobre o tema da migração na literatura de cordel. Para tanto, foram analisados alguns textos literários em diálogo com estudos sobre as migrações internas no Brasil, considerando o contingente de nordestinos que se deslocaram do Nordeste em direção às grandes capitais do Brasil. Foram problematizadas, ainda, as estratégias de construção identitária e as subjetividades evidenciadas a partir da análise de algumas representações elaboradas nos textos populares, tendo em vista as especificidades históricas e sociais da diáspora nordestina.

Palavras-chave: Migrações. Cordel. Nordeste. Identidades. Subjetividades.

Abstract: This article presents a reading on migration issues in the pamphlet literature. Therefore, some literary texts in a dialogue with studies on internal migration in Brazil are analyzed, considering the Northeastern contingent that moved from the Northeast toward the great capitals of Brazil. It is also discussed the identity construction strategies and subjectivities that become evident in the analysis of some representations in popular texts, in view of the historical and social specificities of the Northeastern diaspora.

Keywords: Migrations. Diaspora. Northeast. Identity. Subjectivities.

\section{Apontamentos sobre as migrações internas no Brasil}

Deslocamentos e migrações são temas que hoje estão na ordem do dia. Se antes se falava nesses movimentos a partir de uma ótica reducionista, que encontrava nas determinações econômicas explicação para tais processos; hoje, a análise empreendida sobre tais dinâmicas procura devassar as causas e consequências profundas que levam sujeitos a se deslocarem, problematizando, de modo contumaz, os movimentos migratórios. Corsini (2006), ao analisar a questão, assume o seguinte ponto de vista:

[...] retornar à questão do migrante - sempre associado à figura do Outro, do Estrangeiro - no momento em que as atenções estão voltadas para os embates e conflitos enfrentados pelos integrantes dessas comunidades no contexto da globalização e das novas configurações do trabalho no cenário mundial. Porém, este retorno ao migrante teria de ser feito a partir de novas bases, para além das teorias econômicas neoclássicas, ou ultrapassando a perspectiva integracionista que a supõe que a integração e a ascensão social do migrante em uma nova cultura diferente da sua é a base da construção da cidadania (e da democracia). (CORSINI, 2006, p. 30).

\footnotetext{
* Mestre em Estudos Étnicos e Africanos (UFBA) e doutorando em Estudos Comparados de Literaturas de Língua Portuguesa (USP). Professor da Universidade do Estado da Bahia (UNEB). Endereço eletrônico: joseweltonjr@gmail.com

** Doutora em Estudos Comparados de Literatura de Língua Portuguesa (USP). Professora de Literaturas Africanas de Língua Portuguesa (USP) e do Programa de Pós-graduação em Estudos Comparados de Literaturas de Língua Portuguesa (USP). Endereço eletrônico: rejane.vecchia@gmail.com
} 
Se lançarmos uma breve visada sobre a história do Brasil, não será difícil identificar momentos nos quais as migrações internas aparecem como aspecto formador da nossa sociedade, implicando em deslocamentos traumáticos e construindo novas formas de estar no mundo, conforme indica Gutemberg Guerra (2002, p. 1): "O fenômeno da mobilidade espacial forçada dos camponeses no Brasil, antecede e atravessa toda a história do país". Nesse panorama, o Nordeste emerge como espaço privilegiado de saída de milhares de homens e mulheres em cujo horizonte está a reiterada esperança de melhores condições de vida.

Durante o período colonial, o Nordeste foi, sem dúvida, o território de maior atenção por parte da metrópole, pois condensava em si o status de centro político e econômico da colônia. A região foi identificada como espaço privilegiado para o desenvolvimento das técnicas de exploração, tornando-se lugar de fixação de contingentes metropolitanos, tanto na condição de degredados quanto na de conquistadores imbuídos do projeto de "descoberta" e de ocupação daquelas terras.

Como se sabe, foram nas terras litorâneas baianas que Cabral aportou nos idos de 1500 e foi também nessa porção do que viria a ser o Brasil, que os primeiros colonizadores iniciaram seu empreendimento de conquista. Segundo Caio Prado Junior (1991), o Nordeste se manteve numa situação de destaque frente aos ímpetos colonialistas até pelo menos o século XVIII; todavia, o processo de fixação se deu de forma gradual. Em meados do século XVI, apareceram as primeiras Capitanias Hereditárias, porções de terra doadas a uma pequena nobreza visando a uma exploração mais efetiva do solo colonial. Precisamente nesse período podemos observar o nascimento de uma tradição oligárquica no território brasileiro que só seria abalada com o avanço modernizador do século XX.

As capitanias, por sua vez, foram a mola propulsora para a consolidação da cultura do açúcar no Nordeste. O sistema açucareiro, que teve seu auge entre os séculos XVI e XVII, organizava em torno de si toda dinâmica da colônia e conferia proeminência ao Nordeste. Porém, em finais do século XVII, esse destaque começou a se reduzir, visto que, com as expedições rumo ao interior do país e a procura por ouro em Minas Gerais, as atenções da metrópole, bem como a da população da colônia, foram progressivamente se deslocando da costa e adentrando a colônia. Nesse momento, a capitania de São Vicente começava a se expandir e a vila de São Paulo ganhava relevo.

O século XVIII foi decisivo para o declínio do Nordeste. Com a crise enfrentada pelo açúcar brasileiro, principal produto de exportação, e a ascensão dos açucares produzidos nas Antilhas e do açúcar de beterraba produzido na Europa, a região nordestina, que se organizava em torno da economia de exportação de açúcar, sofreu duros impactos financeiros, levando a indústria açucareira a uma vertiginosa queda. Os antes abastados senhores de engenho e alguns outros indivíduos que enriqueceram com a vertigem do crescimento da economia açucareira, passaram por sérias crises financeiras e muitos tiveram de retornar à economia de subsistência.

Há que se ter em mente, ainda, que esse cenário marcou a vinda da família real portuguesa para o Brasil, implicando em um reordenamento político e geográfico da colônia. O principal acontecimento desse período foi a transferência do centro político da colônia, com a mudança da capital de Salvador para o Rio de Janeiro, contribuindo para o destino de esquecimento do Nordeste do Brasil, que só estaria novamente na ótica do povo brasileiro sob a marca da miséria, do subdesenvolvimento e do abandono.

Nesse contexto de paulatino esquecimento, fundaram-se modos muito específicos de sobrevivência, de modo que a população do Nordeste precisou construir estratégias de permanência para lidar com a permanente ameaça das carências de toda ordem. $\mathrm{O}$ afastamento dos grandes centros políticos fez com que, nesse contexto, imperasse uma 
dinâmica própria de coerção e de poder, pois as poderosas oligarquias governavam as vidas no Nordeste, reiterando uma estrutura social pouco flexível e acentuadamente conservadora. Aos trabalhadores camponeses, desprivilegiados, restava quase sempre a submissão ao mandonismo dos senhores da terra e suas estratégias de violência.

A transição do século XIX para o XX foi marcada por um surto industrial, cujos cenários são as cidades do Rio de Janeiro e de São Paulo, em torno dais quais os portos e os artefactos da vida moderna testemunhavam um inexorável processo de modernização no país. Todavia, esse processo só viria a se consolidar como sistema em meados do século XX, quando, inclusive, a sociedade se define mais claramente em termos de classe. Nesse contexto, o Nordeste ganhou destaque na história nacional, pois é precisamente dessa região que saíram homens e mulheres que contribuíram, como força de trabalho, para o projeto de modernização do país. Inclusive, a denominação Nordeste e muitos dos sentidos aos quais ela remete só se afirmam em meados do século XX. Antes disso, estava associada à região Norte, evidenciando que o país se dividia em um espaço propenso à "evolução: o Sul; e em outra parte que era referência de atraso e de pobreza: o Norte. Assim, nesse período de transformações na economia e na sociedade brasileiras, houve a fixação de estereótipos que marcaram as regiões do Brasil.

Embora as migrações do ciclo da borracha na Amazônia sejam relevantes para um panorama da diáspora nordestina, o período, de fato, mais fecundo para a observação de tais fenômenos é a partir dos anos de 1950. Tendo como principal motivo a busca por trabalho, milhares de homens e mulheres se deslocaram para o centro econômico do país, intensificando a trajetória das migrações internas. A migração de nordestinos em direção ao Sudeste significou a busca por melhores condições de vida e a fuga das consequências econômicas da seca, cuja engrenagem ultrapassa o aspecto climático e se afirma como um instrumento de pauperização da população nordestina.

O movimento de migração, embora tenha o Nordeste como principal espaço de saída, pode ser flagrado em todo país ao longo do século XX, tendo em vista que o Brasil começava a abandonar uma feição eminentemente rural para assumir a imagem de nação moderna, fomentando o crescimento da indústria e das cidades, ao passo que se vislumbrava a formação de uma burguesia nacional e um proletariado urbano. É interessante notar que as oligarquias rurais se envolveram também no processo de modernização se aproximando dos negócios no âmbito do capital estrangeiro. Desse processo, resultou o crescimento demográfico dos grandes centros urbanos, pois tanto ricos quanto pobres viam a cidade como o local prometido. Assim, Caramano e Abramovay (1999) afirmam que:

Os movimentos migratórios respondem pelo processo de esvaziamento da população rural. Em termos nacionais, a intensidade do movimento de desruralização parece não se ter atenuado muitos nos últimos 50 anos [...] entre 1960 e 1980, o êxodo rural brasileiro alcançou um total de 27 milhões de pessoas. Poucos países conheceram movimentos migratórios tão intensos, quer se considere a proporção ou a quantidade absoluta da população atingida. (CARAMANO; ABRAMOVAY, 1999, p. 47).

Como pode ser observado, os movimentos migratórios fazem parte da história moderna do Brasil e isso tem de ser levado em consideração se pensarmos como esses deslocamentos acabam construindo formas peculiares de vivência, já que o deslocamento espacial implica também em um movimento subjetivo, portanto atinge o sujeito nas suas mais diversas dimensões.

Os anos de 1950 merecem destaque nesse percurso, pois foi durante esse período que a migração maciça de contingentes nordestinos produziu o símbolo do pau-de-arara, epíteto 
utilizado para designar o trabalhador rural que contribuiu como força de trabalho para a construção das cidades. Geralmente esses trabalhadores viajavam quilômetros, tendo nenhuma ou pouca garantia de manutenção nos grandes centros, já que eram trabalhadores em regime de semi-servidão. Segundo Caramano e Abramovay (1999), essa década foi a de maior fluxo migratório, cerca de $1 / 3$ da população do Nordeste migrou, pois grandes empreendimentos como a construção de estradas, a construção de Brasília e as plantações de café de São Paulo e do norte do Paraná demandavam mão-de obra barata e pronta para o serviço pesado. As migrações desse período foram motes significativos para a poesia popular, como evidencia o fragmento a seguir:

\section{Saiu o carro da empresa \\ No mundo velho despara \\ O pobre parte chorando \\ Com destino a Guanabara \\ Vai em busca de melhora \\ Levando de mundo afora \\ O nome de Pau-de-arara \\ (O nordestino no Rio)}

Após o modelo pau-de-arara, mantiveram-se os movimentos migratórios. Na década de 1960, houve um arrefecimento da emigração do Nordeste. Segundo estudiosos, esse fenômeno se deu pela redução de oportunidades de trabalho em decorrência do menor crescimento econômico nacional, redundando em um maior contingente migratório advindo das zonas rurais do próprio Sudeste.

Nos anos de 1970, a situação ganha novos contornos, pois volta a haver um crescimento bastante intenso nas taxas de saída do Nordeste. Esse fenômeno pode ser explicado, sobretudo, pelo avanço das atividades pecuaristas, a expulsão generalizada dos "moradores" dos engenhos, bem como as facilidades apresentadas para as migrações internas através de vantagens como o trabalho assalariado, impulsionado pelo milagre econômico. Vemos, portanto, mais uma vez, os processos migratórios se reconfigurarem, uma vez que o crescimento econômico fomentado pelo governo permitiu a saída do migrante, que se deparou com mecanismos de empregabilidade mais sofisticados do que os de outros tempos.

Em relação aos anos de 1980 e 1990, mantiveram-se os fluxos contínuos de trabalhadores saídos do Nordeste, principalmente por conta das estratégias de enraizamento no solo das grandes cidades. A fixação se dava pela possibilidade de moradia que os bairros periféricos ofereciam. Assim, o pobre migrante nordestino deixava de ser símbolo da pobreza da zona rural para ser o miserável das favelas e dos subúrbios, mantendo sua situação de alijamento e de expropriação dos direitos a uma cidadania plena. Dessa forma, foram necessárias estratégias para conquistar direitos elementares, demarcando reconstruções subjetivas e identitárias como índices de resistência a partir de sua condição diaspórica. A síntese de Hall (2003) parece produtiva para avaliar tal cenário:

Nossas sociedades são compostas não de um, mas de muitos povos. Suas origens não são únicas, mas diversas. Aqueles aos quais a terra pertencia, em geral, pereceram há muito tempo - dizimados pelo trabalho e pela doença. A terra não pode ser "sagrada", pois foi "violada" - não vazia, mas esvaziada. Todos que estão aqui pertenciam originalmente a outro lugar. (HALL, 2003, p. 30). 


\section{Cartografias sertanejas: migrações, identidades e subjetividades na poesia popular}

Ao pensarmos nos movimentos migratórios que ocorreram na história do Brasil, acabamos lidando com cifras e percentagens que são indícios das causas pragmáticas que estão na base da questão. Os motivos econômicos despontam repercutindo uma análise demasiadamente objetiva na qual os sujeitos migrantes são entendidos como uma massa indissociável. No entanto, objetivamos, neste trabalho, percorrer um caminho menos "duro", tendo em vista que procuraremos refletir como esses movimentos de ordem pragmática repercutiram e repercutem nas subjetividades dos nordestinos. Para tanto, articularemos o discurso da história - já introduzido na seção anterior - com o discurso da poesia popular, mormente divulgado pela literatura de cordel. Dessa forma, empreendendo uma análise dialética dessas formas de "narração", poderemos avaliar como o êxodo rural está perpetrado no imaginário social, sobretudo o popular, a partir de diferentes modos de representação dos dados históricos mediante o entrecruzamento discursivo que atravessa a materialidade histórica dos sujeitos.

As práticas culturais engendradas pelo povo são maneiras de resistências e de permanência. Dado o contexto das migrações, o fenômeno de articulação da produção artística com a própria vivência do ser nordestino/sertanejo ganha contornos relevantes no que tange à produção de subjetividades e de identidades. Longe de compreendermos a identidade e a subjetividade como conceitos inatos e imutáveis, partimos de uma perspectiva em que esses aparecem como devires, potencialidades em permanente processo de construção e, acima de tudo, como local de afirmação da diferença ou, como quer Félix Guattari (1993), de singularidades frente aos processos de homogeneização empreendidos pela era do capital.

Guattari (1993) chama atenção para a potencialidade da subjetividade em relação ao desnudamento da exploração capitalista, bem como para a necessidade de construção de formas de resistência. Esse fenômeno é denominado de "singularização", definida por ele como uma forma de (re) construção da subjetividade de forma subversiva e desobediente aos modelos impostos pelos detentores dos modos de produção.

Resultado das intersecções entre modelos europeus, africanos e indígenas, a poesia popular sempre foi um campo fértil para reflexão acerca da condição do homem nordestino. Tendo as zonas rurais como lugar privilegiado de desenvolvimento, a literatura popular foi ganhando novos contornos e se transformando paulatinamente. Segundo Doralice Alcoforado (1990), a própria natureza da poesia popular está associada à mutação permanente, tendo em vista os movimentos criativos da oralidade, bem como "a interferência de vários executantes, que intercalam, ao texto recebido, o seu próprio" (p. 36). Portanto, o texto popular, dado os mecanismos de circulação, permite a inovação e a recriação como elementos intrínsecos à estrutura textual.

Dessa forma, os movimentos migratórios ocorridos, principalmente no século $\mathrm{XX}$, são temas recorrentes da literatura popular, de modo que os poetas se ocuparam em recriar experiências suas e de outros nas páginas de cordéis ou em cantorias. Desse movimento, nascem símbolos que recriam os caminhos percorridos e as experiências dos retirantes, obrigados a se retirar de seu território e se lançar em um futuro repleto de incertezas: "parece que nordestino/ nasce com a trouxa pronta" (MARANHÃO, 1996), a fim de conquistar novos espaços e novas formas de significação.

A imagem do retirante é recriada na literatura de cordel das mais diferentes formas. Com frequência, é flagrado o movimento de saída do Nordeste até a chegada ao Sul. Ganha destaque a explicação da causa da saída, que é retomada em vários textos como um "ritual de partida" e a afirmação da necessidade do deslocamento: 
Vendo a má situação

Os pobres sem ter demora

Arrumam seus matulões

E seguem de estrada afora

Como pobres retirantes

Procuram suas melhoras

(O triste drama das secas e o pranto dos nordestinos)

Como podemos observar, a partida rumo a "suas melhoras" passa por um desejo, uma projeção utópica. Segundo Benjamin Abdala Junior (1995), a utopia nasce de um contexto em que a situação vivida exige o reestabelecimento com os fios da esperança, isto é, diante da situação de precariedade vivida no sertão, por conta das secas e das más condições de vida, o sujeito se vê obrigado a emigrar, projetando a cidade no limiar de seus sonhos. Esse "ritual de partida" está presente em uma variedade de textos e é uma forma de evidenciar o caráter compulsório do desligamento, bem como a projeção de um futuro desconhecido, mas hipoteticamente melhor.

Após o deslocamento da terra natal, esse sujeito se torna um ser migrante e, diante disso, novas formas de subjetivação precisam ser engendradas garantindo a sobrevivência de elementos identitários em espaços nos quais assume o lugar do "outro". Segundo Helena (2001, p. 66),

Do ponto de vista formal, a migração indica um dialogismo cultural em que o processo de significação e de construção da subjetividade produzem sentidos móveis, instáveis, em que o "quem sou/quem és" subjaz como problema. (HELENA, 2001, p. 66).

Nesse contexto de inserção, num espaço distinto, os sujeitos são obrigados a reorganizar a sua relação com o espaço ocupado, a partir de um lugar instável e politicamente desprivilegiado. Tal reflexão é possível de ser observada em textos da literatura de cordel, nos quais o migrante/retirante se mostra consciente da espoliação que sofre e enfatiza a necessidade de afirmar sua alteridade, alegando sua participação efetiva na construção dos territórios urbanos:

\author{
São Paulo tem nordestino \\ Muitos mais do que o Norte \\ Trabalham por essa terra \\ Nosso nordestino de pulços de aço \\ Que lutam até a morte \\ (O que faz o nordestino em São Paulo)
}

A afirmação do ser nordestino é uma das preocupações mais evidentes dos textos populares analisados. Este movimento é compreensível se atentarmos para a necessidade de construção identitária nos contextos migratórios. Dessa forma, estamos diante da concepção de identidade como resistência, pois se trata de uma insurgência aos mecanismos de opressão que são acionados para a redução política e existencial de sujeitos a meros objetos com função de produzir bens de consumo.

Levando-se em conta essas tentativas de desmantelamento, a palavra poética aparece como espaço privilegiado para a reflexão acerca da condição de sujeito deslocado e empreende novas formas de significação em torno do processo de deslocamento da terra natal, ensejando estratégias de recomposição simbólica no contexto fraturado grandes cidades. Assim, a poesia popular cumpre o papel de colocar a diferença do nordestino em evidência, 
escolhendo para isso signos que compõem a experiência empírica do diaspórico revivida na memória e no corpo:
Quando saudoso parti,
Com cara de sonhador
A lembrança do lugar
No meu peito se alojou,
No vaivém dos abraços,
Meu coração lá ficou
Deixei o couro das mãos
No cabo da algum machado
Deixei a pele do corpo,
Campeando atrás do gado,
E as cordas do meu canto
Num aboio apaixonado
(Aboio ou a saga do nordestino)

Analisando o papel dos terreiros de candomblé nos grandes centros urbanos, Muniz Sodré (1988) aponta para algumas reflexões entre os sujeitos e os espaços no processo de formulação identitária. Para Sodré (1988), o espaço é peça fundamental para urdidura das identidades, já que os sujeitos, impelidos pela necessidade de significar inata ao homem, necessitam estabelecer uma relação espaço/temporal para desenvolver suas próprias dinâmicas existenciais. Esse espaço sobre o qual se constrói significações se chama território. Por isso, ao falarmos dos migrantes ou diaspóricos, estamos falando de relações de significação com o espaço físico, mas também nos referimos às subjetividades, é o que Guattari (1993) chama de processos de territorialização.

Esses processos são permanentes na nossa vida, pois assumem o movimento, o devir como orientação para a construção de subjetividades e de identidades. Assim, podemos falar em processos de desterritorialização, quando, na arena de significação, nos usurpam o direito de significar; reterritorialização, quando assumimos uma atitude de subversão, questionamento e, sobretudo, reconstrução do direito de significar, metaforicamente, nos situamos no centro da disputa discursiva que dialeticamente recria as tensões sociais nas quais estamos imersos.

Mas, e o migrante, enquanto ser deslocado, como compreende essa relação com o espaço? Acreditamos que o migrante seja um dos emblemas do mundo contemporâneo. Marcado pelo constante exercício de negociação e de resistência, assume uma luta permanente pela recomposição de referenciais, rearticulados pelos impulsos da memória e do desejo de participação social a despeito dos estereótipos engendrados pelo discurso hegemônico. Dessa forma, os processos de subjetivação do ser migrante se apresentam nesse ciclo de negociações, pois, à medida que constrói uma nova experiência no espaço urbano, o sujeito diaspórico constrói modos de resistência, produzindo um perfil nordestino nas grandes cidades, como aparece no trecho a seguir:

Deve ter algum jeito

De não ser burro de carga

Trabalhando obediente

De esporas nas ilhargas,

Tendo que ser sorridente

Embora com a vida amarga.

(Aboio ou a saga do nordestino) 
Como pode ser constatado, o canto do poeta constrói a imagem do trabalhador incansável, mas que revela uma consciência crítica da espoliação e do processo de redução a que é submetido o sujeito no contexto da modernidade capitalista. Em suma, no discurso do sujeito enunciador, o tom pessimista não esconde uma atitude crítica em relação ao trabalho e os arranjos sociais das relações trabalhistas marcados pela exploração.

Nesse processo de construção identititária e subjetivação, o sujeito migrante estabelece um complexo jogo entre lembranças e esquecimentos, plasmando, nos folhetos, traços da memória social que conduzem aos processos de reterritorialização. Sendo assim, deparamo-nos com uma dialética em que lembrança e esquecimento compõem as faces da mesma moeda na tessitura da vida social:

Eu passo horas vagando

Nas praças da imigração

Buscando alguma lembrança

Que me transporte ao sertão,

Um gemido de viola

Que adoece o meu coração.

(Aboio ou a saga do nordestino)

Em seu livro Memória e sociedade, Ecléa Bosi (1994) aponta para a compreensão dessa relação entre memória, indivíduo e sociedade, pois, para além de atividade pessoal, a memória é sempre coletiva, segundo a pesquisadora. A poesia popular se articula com essa perspectiva, tendo em vista que o sujeito poético assume um discurso que agrega experiências múltiplas ao corte autobiográfico que perpassa o texto:
Sabemos que o nortista
pela seca é atacado
sem que o clima é sadio
o povo é muito animado
mas no ano que não chove
todo mundo se comove
tremina despatriado.
(O nordestino no Rio)

Assim, o sujeito enunciador emerge nos versos como uma voz vaticinadora do "destino" dos nordestinos. E se o poeta é a voz que enuncia e denuncia a realidade do povo sertanejo, é também na urdidura dos seus versos que o migrante, na cidade grande, reestabelece os laços com o sertão, criando um espaço simbólico de signos que repercutem em um sentimento de pertencimento, mesmo que momentâneo:

Cada um pede ao poeta

Que relembre seu sertão

Cantam versos de improviso

Tema de amor ou canção

Comem carne e rapadura

Com batida de limão

(O que faz o nordestino em São Paulo) 
As secas, como fato inexorável da vida do nordestino, são a alegoria dos momentos difíceis que, mais cedo ou mais tarde, chegam. Os fatores climáticos e suas consequências sociais aparecem em muitos poemas como a grande explicação para a diáspora. E, assim como os movimentos sazonais, as secas vêm e vão, ao passo que permanece o desejo de retorno ao sertão, no limiar do nordestino/nortista expatriado:

\author{
Chora que faz piedade \\ Chega logo a vontade \\ De volta pra terra sua \\ (...) \\ Quer voltar porém não pode \\ Pra sua terra mimosa \\ (O nordestino no Rio)
}

E ainda dialogando com os versos acima, deparamo-nos com um dado importante para essa reflexão - a distopia recorrente nos poemas em resposta às condições adversas que o homem nordestino passa nos grandes centros. Dessa forma, envolvido na engrenagem do capitalismo, o nordestino pobre que sai de sua terra sustenta o discurso liberal do capitalismo, cujo mote reproduz uma ética acumuladora sob o desejo da ascensão, o que é desconstruído pela experiência concreta da exploração trabalhista, mantendo-se o mesmo estatuto de pobreza ratificado na fixação em favelas e bairros periféricos.

Assim, observamos a modelação de mais uma identidade desse ser migrante, que é a do pobre que vive nos grandes centros urbanos. Walter Benjamin (2006), em sua célebre obra "Passagens", apresenta uma contradição observada na Paris do século XIX e que está na essência das megalópoles: a divisão espacial entre ricos e pobres. E é o embate entre esses dois tipos de territorialidades que constrói a feição de movimento permanente nas grandes cidades. Atentando para essas contradições, o poeta popular canta a precariedade da infraestrutura do circuito inferior, utilizando uma expressão de Milton Santos ${ }^{1}$ :

\author{
Vi as misérias nos morros \\ Que doeu-me o coração \\ Setecentas mil pessoas \\ Que delas eu sou irmão \\ Falta-lhes luz e água \\ Suas casas são tábuas \\ Dormem, em esteiras no chão. \\ (Discussão do pau-de-arara com carioca)
}

Assim, a literatura popular se alimenta também desse discurso frustrado e representa a feição desse homem que, ao mudar a relação com o trabalho, passando para trabalho assalariado, empreende uma nova forma de perceber a sua relação com o espaço citadino. Antes, o espaço prometido, solução para os problemas imediatos causados pela seca e suas consequências, converte-se em cenário de desolação e de carências acrescidas pelo impacto simbólico de existir em novas configurações sociais orientadas pela modernidade capitalista. Sobre isso, vale observar o comentário de Cinea Santos apud Maranhão (1986, p. 1):

\footnotetext{
1 Para o geógrafo brasileiro, a sociedade se divide espacialmente em dois circuitos denominados circuito superior, onde se localizam as instâncias do poder político e econômico, e o circuito inferior, onde os mais pobres se apinham em situação de sub-humanidade.
} 
São trabalhadores maldormidos, famintos, cansados, que se dirigem a seus barracos onde a cidade que edificaram e que mantêm pulsante os esconde [...] Animal essencialmente telúrico, o nordestino forçado pelas contingências, vira ave de arribação e se dilui nos vãos das grandes cidades.

Estamos diante, portanto, de uma prova cabal dessa distopia que aflige as "aves de arribação" que precisam ressignificar o mundo à sua volta. Desse processo de embate entre a cidade e campo, nascem os espaços de negociação. E a literatura popular se lança em um movimento de reorganização, recriando o imaginário nordestino e rural, mas sem negar as penetrações inevitáveis das práticas culturais citadinas na dinâmica de produção e de recepção. Por isso, hoje não é difícil encontrar "aves de arribação", artistas da literatura popular, publicando seus folhetos e encontrando recepção nos milhares de conterrâneos com os quais dividem uma memória coletiva, empreendendo, portanto, modos de singularização, como quer Guattari (1993). Outro exemplo disso são as grandes feiras, lugar, por excelência, de reestruturação de práticas culturais pertencentes ao campo, inclusive ao sertão nordestino:

[...] a presença de migrantes nordestinos no Rio e em São Paulo tem difundido, nessas cidades, hábitos ou usos nordestinos: o de dormir na rede, o de cantar acompanhado de viola, maneira de falar ou uso de certas expressões. A construção civil no Rio de Janeiro tem sido um foco dessa presença, traduzida ainda, de forma bem nítida na feira de São Cristóvão. (DIEGUES JUNIOR, 1986, p. 40).

Para além da busca de uma tradição intocável, observamos a reelaboração dos dados presentes na memória coletiva e no desejo por construir territorialidades que, paralelamente, constroem um ambiente de (re) encontro com determinadas matrizes culturais, bem como a resistência aos processos massificadores de uma sociedade orientada para o lucro, na qual o conceito de subjetividade é convertido em máquina de submissão, moldado por padrões hegemonicamente instituídos. Nesse processo, o sertanejo/migrante se depara diariamente com a luta pela permanência, construindo estratégias de negociação e assumindo o lugar do "outro", do singular, como um modo específico de estar no mundo.

Pensar a diáspora nordestina é, sem dúvida, um exercício que exige uma reflexão tanto mais problematizadora, cujo mapeamento pode ser realizado a partir do acervo da literatura de cordel, como lugar de produção de subjetividades e identidades subalternizadas. Verificamos, portanto, complexas articulações entre dados sociais e psíquicos que impõem modelos de representação quase sempre negligenciados pela cultura hegemônica. Nos vão dessas histórias, pessoais e coletivas, vislumbramos as fissuras dos rostos, as mãos calejadas, os olhos marcados por uma dignidade humana que ultrapassa a ética da exploração, signos produzidos pelas adversidades da vida em constante deslocamento.

Dessa forma, encontramos na poesia popular, nas suas mais diversas modalidades, as cartografias traçadas por nordestinos que se deslocam em busca de um futuro melhor. Hoje, os grandes centros estão apinhados desses sujeitos "acima de tudo, fortes" que se deparam com o desejo de construir sua autoestima positiva apesar das adversidades. Enquanto formulamos hipóteses acadêmicas acerca de todos esses processos complexos, os muitos nordestinos/sertanejos/retirantes permanecem vivendo as dificuldades do solo citadino tendo de lidar com a dureza de mais uma jornada de trabalho longe de sua terra, sem, contudo, esmorecer o sonho de voltar e encontrar abertos os braços áridos do sertão:

Retrato da terra que perdi

Pois logo dali me afastei 
Fui morar bem no Centro da Cidade

Onde sofri tanta perversidade

Que ninguém no mundo há de passar

Procurando da vida a redenção

Eu voltei pro sertão

Porque sei que aqui é meu lugar

(Eu voltei da cidade pro sertão)

\section{Referências}

ABDALA JUNIOR, B. Antônio Jacinto, José Craveirinha, Solano Trindade - O sonho (diurno) de uma poética popular. Via Atlântica, São Paulo, n. 5, p. 30-39, out. 2002.

ALCOFORADO, D. A escritura e a voz. Salvador: Empresa Gráfica da Bahia, 1990.

BARROS, J. A. O que faz o nordestino em São Paulo. [S.1.: s.n].

BENJAMIN, W. Passagens. Belo Horizonte: Editora UFMG; São Paulo: Imprensa Oficial do Estado de São Paulo, 2006.

BOSI, E. Memória e sociedade: lembranças de velhos. São Paulo: Companhia das Letras, 1994.

CARAMANO, A. A; ABRAMOVAY, R. Exxodo rural, envelhecimento e masculinização no Brasil: panorama dos últimos cinquenta anos. Revista Brasileira de Estudos da População, Brasília, v. 15, n. 2, p. 45-66, 1998.

CORSINI, L. Repensando a identidade no contexto de migrações. Psicologia e sociedade, Porto Alegre, v. 18, n. 3, set/dez. 2006.

DIEGUES JÚNIOR, M. et al. Literatura popular em verso: estudos. Rio de Janeiro: MEC/Fundação Casa de Rui Barbosa, 1973.

FERREIRA SOBRINHO, M. O nordestino no Rio. Rio de Janeiro. [s.n], 1996.

GUATTARI, F; ROLNIK, S. Micropolíticas: cartografias do desejo. Petrópolis: Vozes, 1993.

GUERRA, G. A. D. O êxodo rural no cancioneiro popular: Triste partida, de Patativa do Assaré. Trilhas, Belém, v. 3, n. 1, p. 23-34, 2002. Disponível em: < http://www.reformaagrariaemdados.org.br/sites/default/files/O\%20êxodo\%20rural\%20no\%20 cancioneiro\%20popular.\%20Triste\%20Partida,\%20de\%20Patativa\%20do\%20Assaré\%20\%20Gutemberg\%20Armando\%20Diniz\%20Guerra.pdf>. Acesso em: 15 jul. 2016.

HALL, S. Da diáspora: identidades e mediações culturais. Belo Horizonte: Editora UFMG; Brasília: Representação da UNESCO no Brasil, 2003.

HELENA, L. O coração grosso: migração das almas e dos sentidos. Revista Alceu, Rio de Janeiro, v. 1, n. 2, p. 63-76, jan/jun 2001. 
JOÃO PESSOA, S. Eu voltei da cidade pro sertão. [S.1.: s.n], 1990.

MARANHÃO, S. Aboio ou a saga do nordestino. [S.1.: s.n],1986.

MELO NETO, J. C. de. Morte e vida Severina e outros poemas para vozes. Rio de Janeiro: Nova Fronteira, 1994.

OLIVEIRA, F. I. de. Discussão do pau-de-arara com carioca. [S.1.: s.n], [19--].

PRADO JUNIOR, C. Formação do Brasil contemporâneo. São Paulo: Brasiliense, 1991.

SANTOS, A. A. dos. O triste drama das secas e o pranto dos nordestinos. Rio de Janeiro, [19--]. Disponível em: < http://docvirt.com/docreader.net/DocReader.aspx ?bib=cordel\&pagfis=34840\&pesq= $\quad>$. Acesso em: 03 de jul. 2016.

SODRÉ, M. O terreiro e a cidade: a forma social negro-brasileira. Petrópolis: Vozes, 1988.

Recebido em: outubro de 2016.

Aprovado em: dezembro de 2016. 